\title{
TRULY GROSS ANATOMY
}

\section{Sometimes it is necessary to immerse yourself in a subject. Erik Vance meets a woman whose research takes her deep - waist-deep — into cetacean anatomy.}

f you work as a toll collector at the Lincoln Tunnel in
New York City, you might think you've seen it all. Until
the day a woman drives past your booth with a dead
dolphin stuffed in her hatchback.

"I had to fold the front seat over on the passenger's side and shove the bottlenose dolphin's face out of the front passenger window to fit the thing in the car," says Joy Reidenberg, almost losing her breath in laughter at the memory. "And so coming in through the Lincoln Tunnel, they're saying 'What do you have as a passenger?'”

Almost all conversations with Reidenberg, a specialist in cetacean anatomy at the Mount Sinai School of Medicine in New York, end with her deep, hearty laughter. In an age where molecular-level work is king and medical students rarely touch dead bodies, she is one of a handful of researchers left who still embrace the title 'anatomist'. Although colleagues describe her as one of a dying breed, she regularly publishes research that breaks new ground - and maintains that anatomy is as important today as it was in the days of Aristotle.

"But this is not for the weak stomach," she says in her distinctive New York accent. "Breathe through your mouth and hope the wind is strong."

To obtain specimens for her research, Reidenberg has to bring back parts of cetaceans stranded on beaches from Florida to Maine. This means all-day marathons that are a cross between a Jacques Cousteau film and a night at the graveyard. "To bring back a larynx the size of this table," she says, thumping on a conference room table, "takes six people, a tug-of-war, and maybe a backhoe and a crane."

Reidenberg has extracted body parts such as fins, brains and tracheas from all manner of cetaceans, including once from a massive blue whale. This may sound simple, but body parts can weigh tonnes and carcasses are often hard to access. At times she has been chased by sharks, lowered by crane into intestines as deep as a swimming pool, and even pinned against a boat by the errant rolling head of a pilot whale.

Yet she finds plenty of eager volunteers to help. "She was, and is, incredibly passionate about this type of anatomy. And that's pretty infectious," says Armand Balboni, a former student who is now a postdoctoral researcher at Mount Sinai. Her gross anatomy classes are hugely popular - although it's not clear whether this is because of her engaging personality or her habit of bringing whale flippers and sea turtles to class.

But Reidenberg is more than just a popular teacher with an overflowing freezer. She holds academic appointments at the Smithsonian Institution, the Woods Hole Oceanographic Institution and the New York Consortium of Evolutionary Primatology. She has dissected more than 140 cetaceans of various sizes, representing 19 different genera. And she publishes regularly across a wide spectrum of topics.

Much of her work examines the cetacean throat - including how breathing, eating and sound genera-

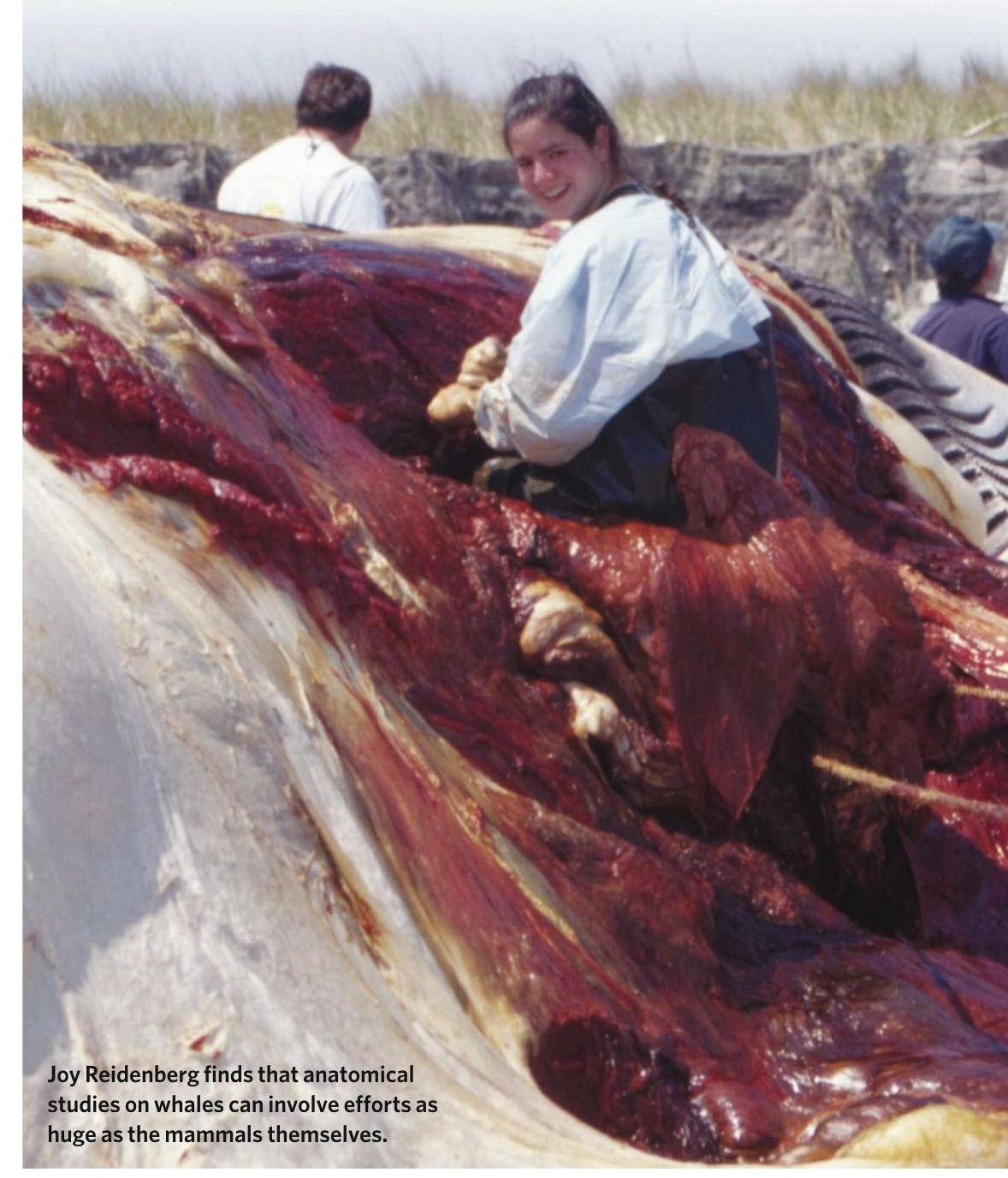

tion work together in an underwater environment. For instance, the mechanisms by which some baleen whales release clouds of tiny air bubbles to confuse prey have long been a mystery. By comparing seven humpback whale carcasses Reidenberg discovered some odd morphology in the epiglottis, a structure that helps separate eating and breathing. She deduced that it is specially formed to flip back and forth, channelling air either to the blowhole or to the mouth, where it would be forced through the baleen as a bubble cloud. This not only answers a question of mechanics, but it means that bubble clouds - which whales may use daily in colder waters - are valuable enough to risk water from the mouth entering the trachea and asphyxiating the animal (J. S. Reidenberg \& J. T. Laitman Anat. Rec. 290, 569-580; 2007).

Reidenberg has also looked into the mystery of sound generation in cetaceans. Vocal folds don't seem to exist in whales, and many researchers have assumed that most 
noises come from the nasal area. But that is because vocal folds in land animals run perpendicular to air flow. Reidenberg discovered a structure in cetacean larynges that runs parallel to air flow, thereby not blocking the airway when it vibrates (J. S. Reidenberg \& J. T. Laitman Anat. Rec. 290, 745-759; 2007). She discovered a similar structure in hippos, the closest living relative to cetaceans.

Evolution of the cetacean voice is still mysterious because the soft tissues of the throat don't fossilize well. But to Reidenberg, her discovery reinforces the idea that whenever possible, nature finds solutions using structures at hand, rather than inventing something new. In the case of whales, low-frequency sound travels well underwater. To make such sounds, you need longer folds. Long folds can't fit perpendicularly across the airway, so nature turned them $90^{\circ}$ for more elbow room.

\section{The fear factor}

Reidenberg's closest associate and mentor, Jeff Laitman of Mount Sinai, co-authored both studies. But as a department head he doesn't always share her enthusiasm. "The two words that have usually sent me into near heart attack have been the words 'mass stranding. To her, this is one of the greatest excitements in the world," he says. "I, on the other hand, have the wonders of explaining to the institutions, the boards, the loading dock, the security people the wonderful material that comes in - trying to stand there with a straight face and say, 'Odour? What odour?"'

With a lab overlooking Central Park, taking up some of the world's most expensive real estate, Laitman says that he cringes every time Reidenberg excitedly calls to say that she has contracted a flatbed truck to bring back some giant specimen. "She's out there and my thoughts are, 'Oh Lord, please let it be something in which the larynx is less than five feet", he says.

There are upsides to the job. For instance, Reidenberg rarely has to open her carry-on luggage once inspectors learn what's inside. And then there was the time she was asked by an airline whether her travel was because of a sudden death. Not thinking, she said it was. She flew to North Carolina under a special rate, presuming she was in mourning for a dead sperm whale.

As a child in suburban Connecticut, Reidenberg says that she was always more interested in trucks and road kill than dolls. Once, at about age eight, she decided one of her few dolls needed a fur coat. Rather than asking her mother for one, she went out and found a dead chipmunk. She flayed it and was drying the hide when, to her horror, a raccoon took her prize.

Today her road kill requires a little more work. In addition to trucks and cranes, a large whale necropsy requires perhaps a dozen people with specialized hooks and knives, which have often been often confiscated from whaling ships that wander into US waters. Dead whales are categorized into one of five codes, based on the level of decomposition. Code 1 is freshly dead, or as Reidenberg says, "like walking into a butcher shop". Code 5 is essentially a dried skeleton. The most common is Code 3, a terrible middle ground where the carcass still contains useful scientific material, but can be best described as putrid. At this stage, the dark red meat has turned tan and is peeling from the body, and

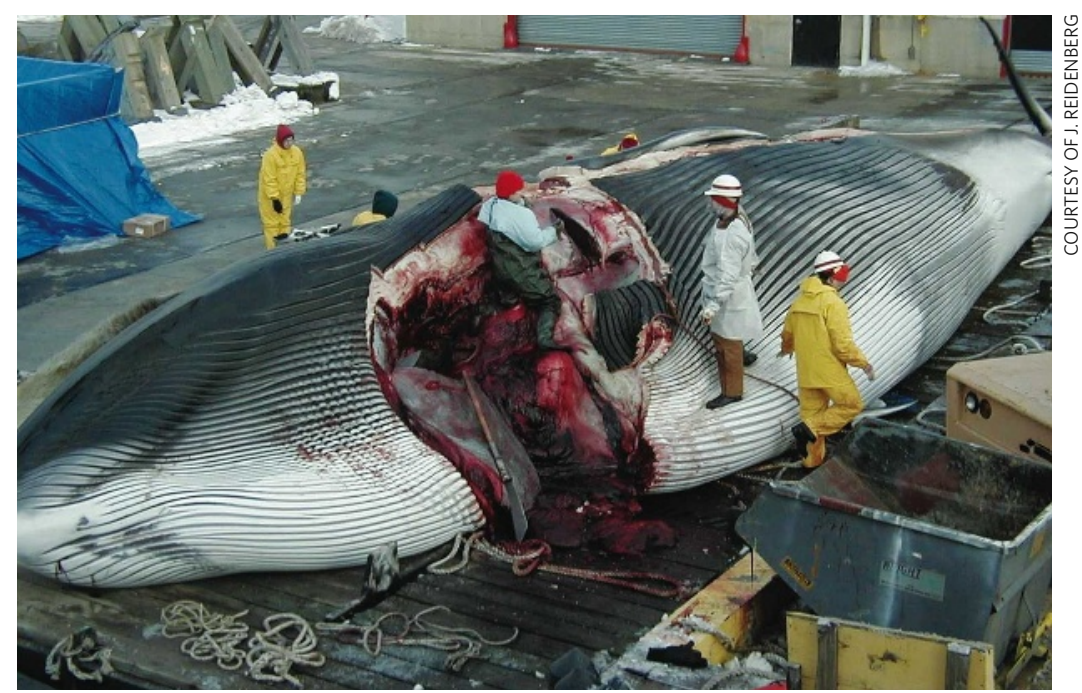

Not in my back yard: this fin whale is in immaculate condition compared with some decomposing cetaceans that wash up.

organs have liquefied into an indecipherable mush.

Many of the best dissections happen in the winter when the animals are preserved by the cold. But the thin latex gloves Reidenberg wears mean that she must intermittently bury her hands in the carcass to stay warm enough to feel her tools. Yet she will happily work for 12 hours extracting a brain that isn't even for her own research.

Lori Marino, a neuroanatomist at Emory University in Atlanta, Georgia, who works with Reidenberg, calls her a "scalpel and table" anatomist. In truth, she is a hammer, chisel, axe, flensing knife and hand-saw anatomist. (She spurns chainsaws for their "fling" factor.) Marino says this gives her a crucial perspective over the entire body that few scientists have in this era of specialization.

Together, Reidenberg and Laitman argue that researchers cannot understand molecular biology or gene expression without better understanding the form and function of anatomy. Further, they say that putting the human body in context requires understanding how it relates to other mammals. Yet anatomy remains a hard field to lure students to, and even harder to find funding in.

Although Reidenberg's work has informed researchers who study human throat maladies such as acid reflux, she admits that it is not the kind of thing that interests important backers such as the National Institutes of Health. In fact it's so hard to get gross-anatomy funding that many medical schools don't expect their professors to publish at all. According to the American Association of Anatomists and various anatomy department heads, this leads to a vicious circle with fewer academics seeing a future in anatomy and then even less funding. "Where is the next generation of anatomists coming from?" asks Reidenberg. "This is a big problem."

She is trying to do her part in her classroom. But if you have a question about a lecture, you may not find her during office hours. That is, unless you are handy with an axe and don't mind the smell.

Erik Vance is a freelance science writer in Berkeley, California. 